\title{
Management of ventricular septal rupture in acute myocardial infarction
}

\author{
M M KHAN, G C PATterson, H O O'KANE, A A J ADGEY \\ From the Regional Medical and Surgical Cardiology Centres, Royal Victoria Hospital, \\ Belfast, $N$ Ireland
}

SUMMARY Four patients with rupture of the interventricular septum after myocardial infarction are described. This condition carries a grave prognosis. Surgical repair of the septum is almost always urgently required if the left-to-right shunt is large $(\mathrm{QP} / \mathrm{QS}>3)$. Results are better if surgery can be deferred for six weeks to allow the infarcted area to heal and the tissues to become firmer. This delay may be achieved by using a combination of agents to reduce afterload and to exert a positive inotropic effect. The timing of surgical intervention was an important factor in the survival of three of the four patients.

Ventricular septal defect after acute myocardial infarction was first described by Latham in $1846 . .^{1}$ Rupture of the ventricular septum occurs within the first few days of myocardial infarction when it is poorly tolerated. It accounts for approximately 0.5 to 1.5 per cent of all deaths from acute myocardial infarction. In the absence of surgical intervention the condition is almost invariably fatal. ${ }^{2}$ Sanders et $a l .^{3}$ found that 54 per cent died within the first week of perforation and only 13 per cent survived two months or longer.

The development of cardiogenic shock and severe left ventricular failure are the most important factors in deciding the outcome. Both are determined by the size of the infarct and the magnitude of the left-to-right shunt. ${ }^{4}$ Repair of ventricular septal rupture was first attempted in $1956 .^{5}$ The optimal time for this is still uncertain; the results of early intervention are poor. ${ }^{6-9}$

This report describes successful repair in three out of four consecutive patients. The time at which operation was undertaken depended on early measurement of the size of the shunt and continuous clinical assessment of the patient.

\section{Case reports}

CASE 1

A 54-year-old housewife was admitted with an acute inferior infarction (Table 1). She was in sinus rhythm (rate $90 / \mathrm{min}$ ) and her blood pressure was $150 / 105 \mathrm{mmHg}$. No murmurs were noted. Within 48 Received for publication 22 April 1980 hours of admission, complete heart block developed, preceded by sinus bradycardia and first and second degree atrioventricular block. The ventricular rate fell to $50 / \mathrm{min}$ and the blood pressure to $80 / 60$ mmHg. Temporary atrioventricular sequential pacing was started. The blood pressure rose to $120 / 80 \mathrm{mmHg}$. Three days later sinus rhythm returned. The same day severe central chest pain recurred. The electrocardiogram showed sinus tachycardia at $120 / \mathrm{min}$, with further ST segment elevation in leads II, III, and aVF. The blood pressure was $105 / 80 \mathrm{mmHg}$. The jugular venous pressure was raised with prominent ' $a$ ' and ' $v$ ' waves. A loud pansystolic murmur accompanied by a thrill was noted at the lower left sternal edge. A Swan-Ganz balloon tip catheter was inserted at the bedside. A large left-to-right shunt (QP/QS 4.8:1) was confirmed at ventricular level (Table 2). Systolic blood pressure had fallen to $65 \mathrm{mmHg}$. Digoxin and diuretics were started along with a dobutamine infusion. In view of the size of the shunt, persistent hypotension, and increasing congestive cardiac failure operation was carried out 10 hours after the development of the ventricular septal defect. At operation the right ventricle was greatly enlarged. The inferior surface of the heart was the site of a large haemorrhagic infarct covering most of the base and extending into the mitral annulus. The left ventricle was opened through its inferior surface using a longitudinal incision through the area of infarction parallel to the posterior descending coronary artery. The mitral apparatus and the papillary muscles appeared 
Table 1 Clinical data

\begin{tabular}{|c|c|c|c|c|c|c|c|c|c|c|c|}
\hline $\begin{array}{l}\text { Case } \\
\text { No. }\end{array}$ & $\begin{array}{c}\text { Age } \\
(y)\end{array}$ & Sex & $M I$ & $\begin{array}{l}M I \text { to } V S D \\
\text { (days) }\end{array}$ & $\begin{array}{l}\text { VSD to } \\
\text { surgery }\end{array}$ & $\begin{array}{l}\text { History of } \\
\text { hypertension }\end{array}$ & $\begin{array}{l}\text { History } \\
\text { of } M I\end{array}$ & $\begin{array}{l}\text { BP on } \\
\text { admission } \\
\text { (mmHg) }\end{array}$ & $\begin{array}{l}\text { Conduction } \\
\text { disturbances }\end{array}$ & Operation & Outcome \\
\hline 1 & 54 & $\mathbf{F}$ & Inferior & 5 & 10 hours & Unknown & 0 & $150 / 105$ & CHB & Repair of VSD & $\begin{array}{l}\text { Alive (died } \\
14 \text { mths } \\
\text { after initial } \\
\text { admission) }\end{array}$ \\
\hline 2 & 59 & $\mathbf{M}$ & Anteroseptal & 10 & 40 days & Yes & 0 & $130 / 80$ & $\begin{array}{c}\text { RBBB and } \\
\text { LAHB }\end{array}$ & $\begin{array}{l}\text { Repair of VSD and } \\
\text { aneurysmectomy }\end{array}$ & Alive \\
\hline 3 & 58 & $\mathbf{F}$ & Anteroseptal & 7 & 40 days & Yes & 0 & $180 / 100$ & $\begin{array}{l}\text { Transient } \\
\text { CHB }\end{array}$ & $\begin{array}{l}\text { Repair of VSD, } \\
\text { aneurysmectomy, } \\
\text { plication of } \\
\text { aneurysm and } \\
\text { SVG to RCA } \\
\text { and Cx }\end{array}$ & Alive \\
\hline 4 & 45 & $\mathbf{M}$ & Anteroseptal & 4 & 26 days & Yes & 0 & $160 / 105$ & None & $\begin{array}{l}\text { Repair of VSD } \\
\text { and plication of } \\
\text { aneurysm }\end{array}$ & $\begin{array}{l}\text { Died at } \\
\text { operation }\end{array}$ \\
\hline
\end{tabular}

MI, myocardial infarction; VSD, ventricular septal defect; CHB, complete heart block; RBBB and LAHB, right bundle-branch block and left anterior hemiblock; SVG, saphenous vein graft; RCA and Cx, right coronary artery and circumflex.

normal. There was a large ventricular septal defect $(2.5 \mathrm{~cm}$ diameter) in the middle third of the septum close to the diaphragmatic surface. The surrounding muscle was necrotic, especially towards the base of the heart. The defect was closed with a Dacron patch applied from the left ventricle and sutured with Teflon pledgets in the right ventricle. The postoperative course was uncomplicated though mechanical respiratory support was required for three days. She remained in sinus rhythm with normal heart sounds and no systolic bruit. Digoxin was continued. On the 23rd postoperative day she was discharged, asymptomatic on moderate activity. She remained well until 14 months later when a further diaphragmatic infarction occurred. She died in cardiogenic shock. Necropsy disclosed that the patch was intact. Extensive recent and old infarcts of the inferior wall were noted, with recent occlusion of the right coronary artery and extensive disease of the left anterior descending and circumflex coronary arteries.

\section{CASE 2}

A 59-year-old company director was admitted with an acute anterior infarction. $\mathrm{He}$ was in sinus rhythm with a blood pressure of $130 / 80 \mathrm{mmHg}$. Forty-eight hours later the electrocardiogram showed bifascicular block (right bundle-branch block and left anterior hemiblock). On the tenth day after infarction a loud pansystolic murmur was noted at the lower left sternal edge accompanied by a thrill. He had not experienced any further chest discomfort.

Cardiac catheterisation with a Swan-Ganz

Table 2 Haemodynamic data

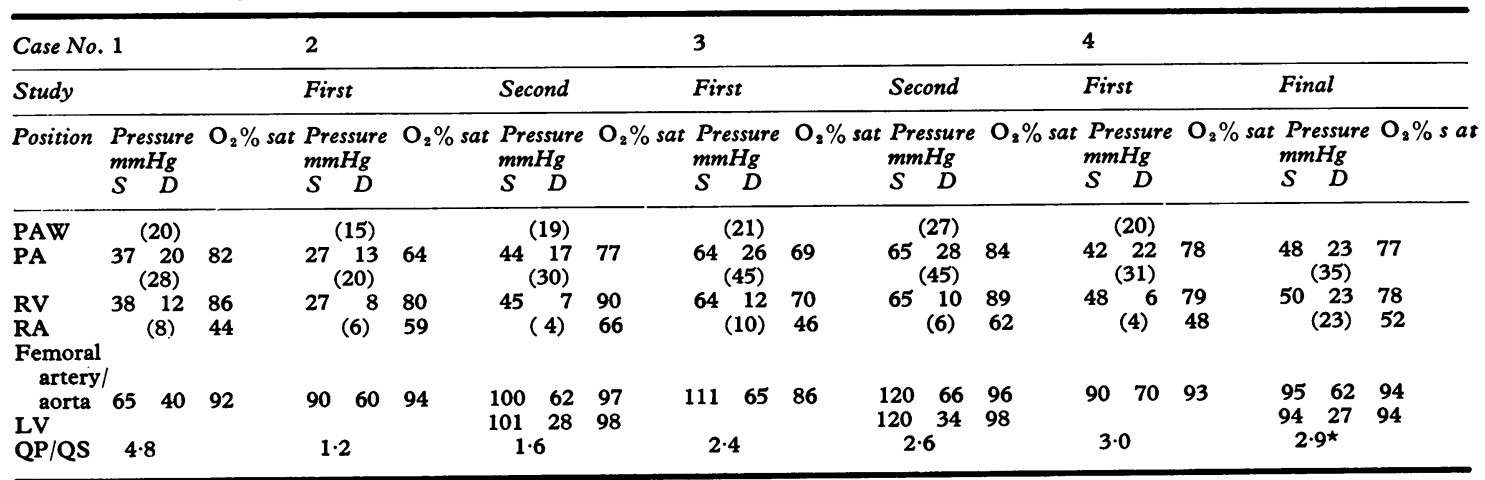

PAW, pulmonary artery wedge; PA, pulmonary artery; RV, right ventricle; RA, right atrium; LV, left ventricle; QP/QS, ratio of pulmonary to systemic flow; S, systolic; $D$, diastolic; ( ), mean.

^Patient had tricuspid regurgitation; QP calculated using mixed venous sample not shown. 
balloon tip catheter was performed. A small left-toright shunt at the ventricular level (QP/QS 1·2:1) was found (Table 2). Treatment with digoxin, diuretics, and labetalol was started. Over the next few days he developed frequent ventricular ectopics which were controlled by oral mexiletine $200 \mathrm{mg}$ tid. Subsequently a gradual increase in the pulmonary vascularity on chest $x$-ray films was noted and the heart became larger, suggesting some increase in the size of the left-to-right shunt. Labetalol was stopped. The heart rate remained at $95 / \mathrm{min}$ and the systolic blood pressure at $90 \mathrm{mmHg}$. Two weeks after ventricular septal rupture, a middiastolic murmur became audible along with third and fourth heart sounds at the apex. Six weeks from the onset of symptoms he underwent cardiac catheterisation and coronary arteriography (Table 2). The shunt was now larger (QP/QS 1·6:1). The left ventricular end-diastolic pressure was conspicuously raised particularly after angiography. There was a large akinetic area involving the anterior wall and apex of the left ventricle. The septum appeared aneurysmal and the septal defect appeared to consist of multiple holes. There was total proximal obstruction of the left anterior descending coronary artery. The right coronary artery showed some narrowing, but this was less than 50 per cent of the lumen. The circumflex vessel was dominant and was normal. Fifty days after the infarction, that is $\mathbf{4 0}$ days after the development of septal rupture, surgical repair was undertaken. The right ventricle and pulmonary artery were tense and enlarged. The left ventricle was opened through the large anterior wall aneurysm, most of which was excised. The aneurysm and scar tissue extended into the ventricular septum. The ventricular septal defect was situated anteriorly in the middle third of the septum, and was approximately $2 \mathrm{~cm}$ in diameter and fenestrated. It was closed from the left side with a patch of knitted Dacron, and sutured in place with interrupted Prolene sutures on pledgets on the right side of the septum. After operation bifascicular block persisted. Ventricular ectopics developed seven days later. These were not controlled by mexiletine, quinidine, procainamide, or disopyramide but propranolol $160 \mathrm{mg}$ orally daily was added to mexiletine $150 \mathrm{mg}$ tid and a permanent sequential atrioventricular pacemaker programmed for a rate of $70 / \mathrm{min}$ was inserted. The ectopics were considerably diminished. He remained asymptomatic on moderate activity and went home 33 days after the operation. He has remained well and free from angina for 13 months since operation.

\section{CASE 3}

58-year-old housewife was admitted with an acute anterior infarction. She was in sinus rhythm (rate $90 / \mathrm{min}$ ) and her blood pressure was $180 / 100$ $\mathrm{mmHg}$. Over the next 12 hours she experienced further chest pain and the ST segment in the anterior chest leads became higher. Her pain was controlled with diamorphine, sublingual isosorbide dinitrate, and propranolol. The blood pressure was $140 / 85 \mathrm{mmHg}$. ST segments became isolectric on the fifth day. On the seventh day she experienced further chest pain. Sinus tachycardia at $110 / \mathrm{min}$ was present, the blood pressure was $140 / 95 \mathrm{mmHg}$, and the jugular venous pressure was raised 2 to $3 \mathrm{~cm}$. A loud pansystolic murmur accompanied by a thrill was noted along the lower left sternal edge. An electrocardiogram showed recurrence of ST segment elevation in anterior chest leads. A Swan-Ganz balloon catheter was inserted and a left-to-right shunt at ventricular level (QP/QS 2.4/1) was confirmed (Table 2). She was treated with digoxin and diuretics and, in an effort to reduce the afterload, oral isosorbide dinitrate $30 \mathrm{mg}$ qid and labetalol $100 \mathrm{mg}$ tid were given. The latter was added to prevent an excessive rise in heart rate in response to peripheral vasodilatation. The systolic blood pressure was maintained at $100 \mathrm{mmHg}$; the heart rate was $90 / \mathrm{min}$. Initially she improved but over the next 24 to 48 hours the urine output fell and the plasma urea rose. A chest film showed an increase in pulmonary vascular congestion. The jugular venous pressure remained high. A dobutamine infusion $(5 \mu \mathrm{g} / \mathrm{kg}$ per min) was started. The combination of afterload reduction and inotropic support with dobutamine resulted in increased urinary output and a fall in the plasma urea. The venous pressure became normal. Dobutamine was withdrawn and 10 days later labetalol was stopped. The systolic blood pressure remained at 90 to $100 \mathrm{mmHg}$ and the heart rate at 90 to $110 / \mathrm{min}$. The dobutamine infusion was restarted three weeks after septal rupture when the plasma urea again increased and urinary output decreased and once more a good response was obtained. It was stopped after three days. Except for one episode of sinus bradycardia and transitory complete heart block, sinus rhythm was retained. Six weeks from the onset of symptoms cardiac catheterisation (Table 2) showed a large ventricular septal defect and a large anteroseptal aneurysm. Coronary angiography showed triple vessel disease. The left anterior descending coronary artery had a 60 per cent stenosis near its origin. The distal vessel was of small calibre and appeared to be recanalising. There was a single localised stenosis greater than 70 per cent in both the circumflex and right coronary arteries. The distal vessels were of good calibre. At operation 40 days after the development of the ventricular septal defect, the right 
ventricle was moderately enlarged and was under high pressure. There were two aneurysms of the left ventricle. The smaller was to the right of the left anterior descending coronary artery, and the larger, to the left of it, extended from the upper third of the anterior wall to the apex. The left ventricle was opened through the larger aneurysm. The ventricular septal defect was situated anteriorly in the middle third of the septum and was divided by trabeculae into two parts. The overall area was about $3 \mathrm{~cm}^{2}$. It was closed with a Teflon patch. The larger of the two aneurysms was removed and the other plicated. Saphenous vein grafts were inserted into the circumflex and right coronary arteries. Postoperatively no murmur was audible. Sinus rhythm was retained. Digoxin and diuretic therapy were continued and the patient was discharged from hospital 15 days after operation. She remained well until six months after operation when she stopped taking digoxin and diuretics and was readmitted to hospital in congestive heart failure. This responded to treatment. No murmur was noted.

\section{CASE 4}

A 45-year-old textile worker was admitted with an acute anterior infarction. On admission he was in sinus rhythm (rate $90 / \mathrm{min}$ ) and his blood pressure was $160 / 105 \mathrm{mmHg}$. He had had rheumatoid arthritis for the previous four years and was being treated with prednisolone $6 \mathrm{mg}$ daily. On the fourth day after the onset of symptoms a systolic murmur was noted at the lower left sternal edge. He was still in sinus rhythm at $100 / \mathrm{min}$ and the blood pressure was $140 / 90 \mathrm{mmHg}$. Propranolol $10 \mathrm{mg}$ tid and quinidine $500 \mathrm{mg}$ twice daily were started; prednisolone was continued. On the tenth day after admission he became acutely dyspnoeic. Hypotension and signs of biventricular failure were present. Fivehundred $\mathrm{ml}$ blood were removed by venesection, and digoxin, frusemide, and a dopamine infusion were started. He was transferred to our unit for further management.

Right heart catheterisation was performed with a Swan-Ganz balloon catheter and confirmed rupture of the ventricular septum with a large left-to-right shunt ( $\mathrm{QP} / \mathrm{QS} 3: 1$ ) (Table 2). After giving $5 \mathrm{mg}$ isosorbide dinitrate sublingually the mean pulmonary artery wedge pressure fell. There was an increase in systemic flow, but no change in pulmonary flow and the shunt diminished (Table 3). A nitroprusside infusion of $70 \mu \mathrm{g} / \mathrm{min}$ was started together with oral isosorbide dinitrate $120 \mathrm{mg}$ daily (Table 3 ). Digoxin and frusemide were continued. Over the next 48 hours the mean pulmonary artery wedge and pulmonary artery pressures fell. The arterial pressure remained unchanged (Table 3). The nitroprusside infusion was stopped three days later and replaced by labetalol $200 \mathrm{mg}$ tid orally in an effort to reduce the afterload and at the same time prevent a disproportionate rise in the heart rate. Twentyfour hours later the systolic blood pressure fell to $80 \mathrm{mmHg}$ and plasma urea rose. Labetalol was reduced to $100 \mathrm{mg}$ orally tid and a dobutamine infusion (500 mg 12 hourly) was started. Immediate improvement in the blood pressure was noted and in the urinary output. Labetalol was stopped after a further three days. Over the next two weeks as isosorbide dinitrate and digoxin were continued with intermittent diuretics, there was $x$-ray evidence

Table 3 Haemodynamic response to vasodilator treatment in case 4

\begin{tabular}{|c|c|c|c|c|c|c|c|c|c|c|c|c|}
\hline & \multicolumn{4}{|c|}{ On admission } & \multicolumn{4}{|l|}{ Day one } & \multicolumn{4}{|l|}{ Day two } \\
\hline & \multicolumn{2}{|l|}{ Control } & \multicolumn{2}{|l|}{$\begin{array}{l}\text { Isosorbide } \\
\text { dinitrate } \\
5 \mathrm{mg} \mathrm{SL}\end{array}$} & Control & & \multicolumn{2}{|c|}{$\begin{array}{l}\text { Nitroprusside } \\
70 \mu \mathrm{g} / \mathrm{min}\end{array}$} & \multicolumn{2}{|l|}{ Control } & \multicolumn{2}{|c|}{$\begin{array}{l}\text { Nitroprusside } \star \star \\
70 \mu g / m i n \text { and } \\
\text { isosorbide dinitrate } \\
5 \mathrm{mg} S L\end{array}$} \\
\hline Position & $\begin{array}{l}\text { Pressure } \\
m m H g \\
S \quad D\end{array}$ & $\mathrm{O}_{2} \%$ sat & $\begin{array}{l}\text { Pressure } \\
m m H g \\
S \quad D\end{array}$ & $\mathrm{O}_{2} \%$ sat & $\begin{array}{l}\text { Pressure } \\
m m H g \\
S \quad D\end{array}$ & $\mathrm{O}_{2} \%$ sat & $\begin{array}{l}\text { Pressure } \\
m m H g \\
S \quad D\end{array}$ & $\mathrm{O}_{2} \%$ sat & $\begin{array}{l}\text { Pressure } \\
m m H g \\
S \quad D\end{array}$ & $\mathrm{O}_{2} \%$ sat & $\begin{array}{l}\text { Pressure } \\
m m H g \\
S \quad D\end{array}$ & $\mathrm{O}_{2} \%$ sat \\
\hline PAW & (20) & & (10) & & (19) & & (16) & & (23) & & (15) & \\
\hline PA & $\begin{array}{l}4222 \\
(31)\end{array}$ & 78 & $\begin{array}{c}3518 \\
(26)\end{array}$ & 79 & $\begin{array}{c}34 \quad 20 \\
(28)\end{array}$ & 81 & $\begin{array}{c}2816 \\
(22)\end{array}$ & 83 & $\begin{array}{c}42 \quad 26 \\
(34)\end{array}$ & 81 & $\begin{array}{c}3018 \\
(24)\end{array}$ & 81 \\
\hline RA & (4) & 48 & (4) & 55 & & 56 & & 62 & & 58 & & 62 \\
\hline FA/Rad A & $\begin{array}{c}9070 \\
(79)\end{array}$ & 93 & $\begin{array}{c}9268 \\
(79)\end{array}$ & 94 & $\begin{array}{c}94 \quad 69 \\
(82)\end{array}$ & 94 & $(80)$ & 96 & $\begin{array}{c}10570 \\
(85)\end{array}$ & 94 & $\begin{array}{l}10070 \\
(85)\end{array}$ & 94 \\
\hline $\begin{array}{l}\text { Systemic } \\
\text { flow } 1 / \mathrm{min}^{\star}\end{array}$ & $\star \quad 3.2$ & & $3 \cdot 8$ & & $3 \cdot 3$ & & $3 \cdot 7$ & & $3 \cdot 4$ & & $3 \cdot 9$ & \\
\hline
\end{tabular}

FA/Rad A, femoral artery/radial artery. Other abbreviations as in Table 2.

$\star$ Flows measured by thermodilution.

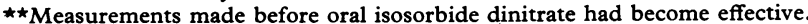


of a gradual increase in heart size and pulmonary vascular congestion. Two further temporary infusions of dobutamine were required. Thirty days from the onset of symptoms, cardiac catheterisation and coronary angiography were performed. The left ventricle was very dilated with a large aneurysmal sac involving most of the anterolateral wall. There was a large left-to-right shunt through the ventricular septal defect. The right ventricle was dilated and there was some tricuspid regurgitation. The right ventricular end-diastolic pressure was $23 \mathrm{mmHg}$ and the mean right atrial pressure was $23 \mathrm{mmHg}$. Coronary angiography showed widespread atheroma with total proximal occlusion of the left anterior descending artery and extensive disease in the right coronary artery. The circumflex vessel was non-dominant and showed some narrowing at the origin of the obtuse marginal branch. These vessels were not suitable for saphenous vein grafting.

Surgery was carried out on the same day. The left ventricle was opened through the aneurysm. A large ventricular septal defect was situated anteriorly in the middle third of the septum measuring $2 \mathrm{~cm}$ in diameter. The edges of the defect were ragged and surrounded by necrotic tissue. The ventricular septal defect was closed with a Dacron patch on the left ventricular side and Teflon pledgets on the right ventricular side. The left ventricular aneurysm was plicated. The mitral valve was normal. The tricuspid valve was not regurgitant. Right ventricular pressure remained high and bypass could not be discontinued despite numerous and prolonged attempts. A further plication of an akinetic area of the left ventricle was carried out. The distal third of the right ventricle was akinetic. Exploration with a finger of the right ventricle showed that there was no residual shunt, yet, despite numerous attempts the left ventricle was unable to sustain an adequate pressure and the patient died.

At necropsy severe atheroma of the coronary arteries with a recent thrombotic occlusion of the left anterior descending artery were confirmed. There was massive recent infarction of the septum and the left ventricle. A healed infarct in the territory of the obtuse marginal branch was noted. The right ventricle was dilated and showed extensive areas of fibrosis and some infarction of the distal part. The patch closure of the defect was intact.

\section{Discussion}

After acute myocardial infarction it is often difficult to distinguish between a ventricular septal defect and mitral regurgitation secondary to papillary muscle dysfunction or rupture. Rapid confirmation of the diagnosis of a ventricular septal rupture can be carried out at the bedside by right heart catheterisation using a balloon-tip flow-directed catheter. Mitral regurgitation is diagnosed by giant ' $\mathrm{V}$ ' waves recorded in the pulmonary wedge pressure tracing. Mitral regurgitation and ventricular septal rupture rarely occur together. ${ }^{10}$ Coronary arteriography and left ventricular angiography carried out early after the ventricular septal rupture are associated with a high morbidity and mortality. ${ }^{11}$

Septal rupture complicates anterior and inferior infarctions with equal frequency ${ }^{4}$ and there is good correlation between its position and the electrocardiographic location of infarction, ${ }^{11}$ as our patients showed.

Conduction disturbances are common. In five patients with acute inferior infarction James ${ }^{12}$ described varying degrees of atrioventricular block before ventricular septal rupture. Vlodaver and Edwards ${ }^{13}$ observed atrioventricular conduction disturbances in 36 per cent of 17 patients with acquired ventricular septal defects, the majority of whom had had an anterior infarction. Complete heart block occurred in two of our patients, one (case 1) with an inferior and the other (case 3) with an anterior infarction (Table 1). In case 1 atrioventricular conduction disturbance occurred before septal rupture and in case 3, transitorily, after it. One patient with anterior infarction (case 2) developed bifascicular block before septal rupture.

Post-infarction septal defects are located in the muscular part of the septum and are associated with a high incidence of left ventricular aneurysm. ${ }^{14}$ Schlesinger et al. ${ }^{15}$ found that more than 30 per cent of patients operated on for septal rupture had a ventricular aneurysm, and Hill et al. ${ }^{16} 68$ per cent. Three of our patients had ventricular aneurysms. In the remaining patient who had surgery five days after infarction (10 hours after septal rupture) there was a large necrotic area in the inferior wall but no aneurysm.

The precipitating factors in ventricular septal rupture are unknown. It has been suggested that hypertension is important. ${ }^{17}$ Three of our four patients had this on admission and the other, while normotensive, had a history of hypertension.

Three to six months after infarction, surgical repair of a ventricular septal defect is associated with a very low mortality ${ }^{18-20}$ but septal rupture usually occurs in the first week after infarction, and, with acute volume overload of both ventricles superimposed on an infarcted left ventricle, sudden 
clinical deterioration and progressive, refractory congestive heart failure and often cardiogenic shock mean that most patients do not survive that long. However, successful early closure has been reported within three weeks of infarction, ${ }^{11} 18$ 21-23 though only 50 per cent or less of these patients survived to leave hospital. ${ }^{182223}$ The earliest attempt at closure has been within the first 24 hours. ${ }^{11}$ In view of the high mortality of early correction it has been suggested that closure should be delayed until four to six weeks after infarction, ${ }^{919} 21$ but the optimal time is dictated by the size of the shunt determined as early as possible after septal rupture. Mundth et al. ${ }^{24}$ suggested that operation should be considered in patients with a $\mathrm{QP} / \mathrm{QS}$ of more than $3: 1$ and acute and refractory clinical deterioration within the first two weeks. Our findings support this view. Our first patient with an inferior infarction had a shunt of 4.8:1 complicated by rapid clinical deterioration within the first 10 hours and needed early surgery. The other three had shunts of $3: 1$ or less and it was possible to delay operation. Acquired septal defects after inferior infarction are often larger than those associated with anterior infarction and thus carry a worse prognosis ${ }^{25}$; surgical correction is difficult and rarely successful. Our single patient had successful surgery carried out 10 hours after the occurrence of the defect. To delay operation until approximately six weeks after infarction in our other three patients, a combination of drugs which have a positive inotropic effect and those which reduce afterload were used. The latter, that is isosorbide dinitrate, nitroprusside, and labetalol, lower peripheral vascular resistance and impedance to left ventricular ejection, thereby improving systemic blood flow. ${ }^{26}{ }^{27}$ Synhorst et al. ${ }^{28}$ created ventricular septal defects in dogs. After the administration of vasodilators the size of the shunt was reduced because of the different effects on the total pulmonary and systemic vascular resistances. In patients with post-infarction septal rupture, however, DiSegni et al. ${ }^{27}$ found that though these agents reduced pulmonary wedge pressure and improved left ventricular function the size of the left-to-right shunt was not altered significantly. If left ventricular function improves and pulmonary artery wedge pressure falls, pulmonary artery pressure will also be reduced. This will offset the reduction in systemic vascular resistance. Thus, in case 4 (Table 3) the systemic flow increased slightly, but pulmonary flow remained unchanged, and hence the flow across the septal defect was unaltered, though $\mathrm{QP} / \mathrm{QS}$ fell slightly. These agents should be used with caution. In patients with right ventricular involvement a fall in venous return, even in the presence of significant left-to-right shunting, may decrease right ventricular stroke volume. ${ }^{4}$ Furthermore, lower blood pressure may reduce renal blood flow, as occurred in two of our patients, who then needed positive inotropic drugs.

Initial attempts at surgical repair were carried out via the right ventricle but were associated with poor results. There was difficulty in defining the borders of the defect, and when multiple defects were present they were concealed by the trabeculae of the right ventricle. The incidence of a residual defect and subsequent mortality was very high. The approach is now from the left ventricle where a clear view of the interventricular septum is obtained. ${ }^{629}$ The patch is put on from the high pressure side of the defect, diminishing the risk of recurrence. The left ventricle is entered by incising or resecting the area of infarction or the commonly coexisting aneurysm, which three of our patients had. The defect was successfully repaired in three of our patients and no recurrence has been detected. The remaining patient died at operation as a result of extensive infarction and severe coronary atheroma.

\section{References}

1 Latham PM. Lecture XXVI. Case of rupture of the heart. In: Lectures on subjects connected with clinical medicine, comprising Diseases of the Heart. London: Longman, 1846; II : 168-76.

2 Lee WY, Cardon L, Slodki SJ. Perforation of infarcted interventricular septum. Arch Intern Med 1962; 109: 731-41.

3 Sanders RJ, Kern WH, Blount SG Jr. Perforation of the interventricular septum complicating myocardial infarction. Am Heart f 1956; 51: 736-48.

4 Fox AC, Glassman E, Isom OW. Surgically remediable complications of myocardial infarction. Progr Cardiovasc Dis 1979; 21: 461-84.

5 Cooley DA, Belmonte BA, Zeis LB, Schnur S. Surgical repair of ruptured interventricular septum following acute myocardial infarction. Surgery 1957; 41: 930-7.

6 Kitamura S, Mendez A, Kay JH. Ventricular septal defect following myocardial infarction. $\mathcal{f}$ Thorac Cardiovasc Surg 1971 ; 61: 186-99.

7 Shumacker HB Jr. Suggestions concerning operative management of postinfarction septal defects. $\mathcal{F}$ Thorac Cardiovasc Surg 1972; 64: 452-9.

8 Lufschanowski R, Angelini P, Del Rio C, Hallman GL, Cooley DA, Leachman RD. Ventricular septal rupture, secondary to myocardial infarction. Chest 1974; 65: 59-63.

9 Donahoo JS, Brawley RK, Taylor D, Gott VL. Factors influencing survival following postinfarction ventricular septal defects. Ann Thorac Surg 1975; 19: $648-53$.

10 Gowda KS, Loh CW, Roberts R. The simultaneous occurrence of a ventricular septal defect and mitral 
insufficiency after myocardial infarction. Am Heart f 1976; 92: 234-36.

11 Kaplan MA, Harris CN, Kay JH, Parker DP, Magidson O. Postinfarctional ventricular septal rupture. Chest 1976; 69: 734-38.

12 James TN. De Subitancis mortibus-XXIV. Ruptured interventricular septum and heart block. Circulation 1977; 55: 934-46.

13 Vlodaver Z, Edwards JE. Rupture of ventricular septum or papillary muscle complicating myocardial infarction. Circulation 1977; 55: 815-22.

14 Selzer A, Gerbode F, Kerth WJ. Clinical, haemodynamic, and surgical considerations of rupture of the ventricular septum after myocardial infarction. $\mathrm{Am}$ Heart f 1969; 78: 598-607.

15 Schlesinger Z, Lieberman Y, Landesberg A, Neufeld HN. Repair of ventricular septal defect and left ventricular aneurysm following myocardial infarction. Thorax 1971; 26: 615-8.

16 Hill JD, Lary D, Kerth WJ. Gerbode F. Acquired ventricular septal defects. Evolution of an operation, surgical technique, and results. $\mathcal{F}$ Thorac Cardiovasc Surg 1975; 70: 440-50.

17 Iben AB, Pupello DF, Stinson EB, Shumway NE. Surgical treatment of postinfarction ventricular septal defects. Ann Thorac Surg 1969; 8: 252-62.

18 Buckley MJ, Mundth ED, Daggett WM, DeSanctis RW, Sanders CA, Austen WG. Surgical therapy for early complications of myocardial infarction. Surgery 1971; 70: 814-20.

19 Giuliani ER, Danielson GK, Pluth JR, Odyniec NA, Wallace RB. Postinfarction ventricular septal rupture. Surgical considerations and results. Circulation 1974; 49: 455-9.

20 Daggett WM, Guyton RA, Mundth ED, et al. Surgery for post-myocardial infarct ventricular septal defect. Ann Surg 1977; 186: 260-71.

21 Stinson EB, Becker J, Shumway NE. Successful repair of postinfarction ventricular septal defect and biventricular aneurysm. $\mathcal{f}$ Thorac Cardiovasc Surg 1969 ; 58: 20-4.

22 Graham AF, Stinson EB, Daily PO, Harrison DC. Ventricular septal defects after myocardial infarction. Early operative treatment. $\mathcal{J} A M A$ 1973; 225: 708-11.

23 Windsor HM, Shanahan MX, Chang VP. Perforation of the interventricular septum complicating myocardial infarction. Med f Aust 1978; 1: 587-90.

24 Mundth ED, Buckley MJ, Daggett WM, Sanders CA, Austen WG. Surgery for complications of acute myocardial infarction. Circulation 1972; 45: 1279-91.

25 Kahn J-C, Rigaud M, Gandjbakhch I, Bardet J, Bensaid J, Bourdarias J-P. Posterior rupture of the interventricular septum after acute myocardial infarction: successful early surgical repair. Ann Thorac Surg 1977; 23: 483-6.

26 Tecklenberg PL, Fitzgerald J, Allaire BI, Alderman EL, Harrison DC. Afterload reduction in the management of postinfarction ventricular septal defect. Am F Cardiol 1976; 38: 956-8.

27 DiSegni E, Kaplinsky E, Klein HO, Levy $M$. Treatment of ruptured interventricular septum with afterload reduction. Arch Intern Med 1978; 138: 1427-9.

28 Synhorst DP, Lauer RM, Doty DB, Brody MJ. Hemodynamic effects of vasodilator agents in dogs with experimental ventricular septal defects. Circulation 1976; 54: 472-7.

29 Javid H, Hunter JA, Najafi H, Dye WS, Julian OC. Left ventricular approach for the repair of ventricular septal perforation and infarctectomy. $f$ Thorac Cardiovasc Surg 1972; 63: 14-24.

Requests for reprints to Dr A A J Adgey, Regional Medical Cardiology Centre, Royal Victoria Hospital, Grosvenor Road, Belfast BT12 6BA, Northern Ireland. 